\title{
A Experiência Perceptual na Perspectiva da TEORIA DA PERCEPÇÃo DiRETA
}

\author{
MARIANA C. BROENS
}

\begin{abstract}
The objective of this paper is to analyse the concept of skilful action underlying the studies of perceptual experience, especially the visual one, from the perspective of the theory of direct perception. The problem we propose to investigate can be formulated as follows: what are the possible contributions of the concept of affordance to understand the nature of skilful actions generally attributed to processes resulting from internal representations or mental models? In particular, we will try to investigate to what extent the concept of social affordance (as a possibility of action that the bodies of the organisms offer directly to other organisms) can help to understand aspects of complex skilful actions that involve capacities considered as deriving from the possession of a Theory of Mind. We will try to show that the perspective of the ecological psychology of direct perception (Gibson 1986, Turvey 1992, Petrusz \& Turvey 2010) allows to understand aspects of human skilled action, especially of a collaborative nature, from a conception of perceptual experience that involves information intrinsically significant.
\end{abstract}

Keywords: Experience; theory of perception/action; affordance; mutuality; complex skills; cooperative action.

\section{Introdução}

Defensores da Teoria Representacional da Mente (TRM) consideram que ações habilidosas em geral resultariam de processos cognitivos mediados por representaçõe mentais ou delas resultantes. Em especial, Jerry Fodor e Zenon Pylyshyn apresentam pressupostos básicos dessa teoria em sua recente obra intitulada Minds without Meanings: An Essay on the Content of Concepts. Nessa obra, os autores reafirmam teses centrais da TRM dentre as quais destacamos as seguintes: (1) a abordagem behaviorista estaria equivocada pois as ações humanas seriam efeitos de causas mentais (a ação resultaria das crenças, intenções, desejos e outras atitudes proposicionais do agente); (2) as representações mentais seriam parte do mundo físico; (3) elas seriam "discursivas", isto é, análogas à linguagem, e de natureza composicional, ou seja, do mesmo modo que as proposições da linguagem comum, as representações mentais expressariam adequadamente relações entre seus elementos constituintes; (4) os processos cognitivos consistiriam em cadeias causas de ocorrências (tokens) de representações internas e tais processos seriam computáveis, isto é, seriam: “...operações estabelecidas sobre as estruturas constituintes das representações mentais dos conceitos e proposições aos quais se aplicam e que podem complementar, apagar ou reorganizar"

Principia 21(2): 223-233 (2017).

Published by NEL — Epistemology and Logic Research Group, Federal University of Santa Catarina (UFSC), Brazil. 
(2014, p.11). Considerando estas teses, na perspectiva da teoria representacional da mente, a experiência forneceria apenas parte da informação necessária para a criação de modelos mentais por meio de processos internos que envolvem representações mentais, os quais, uma vez criados, ofereceriam a base para o planejamento e efetivação da ação.

No entanto, sem pretender debater a natureza e o papel eventualmente desempenhado por representações mentais nos processos cognitivos, pretendemos aqui apenas destacar que tal abordagem suscita vários problemas para a compreensão da natureza de ações que dificilmente podem ser explicadas como mediadas e causadas por representações mentais (Haselager 2004). Esse parece ser o caso de ações que envolvem conhecimento comum e habilidades complexas dos seres humanos (e de muitos outros organismos), especialmente aquelas relacionadas aos diferentes padrões/modos de interação social.

Alguns dos problemas que abordagens representacionistas não parecem capazes de enfrentar dizem respeito, por exemplo, (a) à natureza de ações espontâneas praticadas em situações limite que não decorrem de processos inferenciais de tomada de decisão, (b) a dificuldade de determinar e comunicar as motivações da ação que, no entanto, supostamente desempenhariam um papel causal em ações deliberadas, (c) à dificuldade de aprender/ensinar através da narrativa de experiências de outrem, para citar apenas alguns. Sem pretender solucionar estes e outros problemas semelhantes neste texto, consideramos que a teoria ecológica da percepção direta pode nos auxiliar a compreender aspectos importantes do papel desempenhado pela experiência perceptiva, especialmente a visual, no exercício de ações habilidosas.

A análise das possíveis contribuições de uma abordagem não representacionista da experiência será realizada a partir da teoria ecológica da percepção/ação, também conhecida como teoria da percepção direta (Gibson 1986, Turvey 1992, McArthur \& Baron 1984). Nossa hipótese é que tal análise poderá contribuir para a compreensão de características centrais de ações relacionadas a habilidades sociais complexas, as quais, na perspectiva da TRM, são, ao contrário, consideradas dependentes de processos inferenciais mediados por representações mentais.

De modo a investigar tal hipótese, o presente texto será dividido em duas seções. Na primeira, apresentaremos conceitos centrais da teoria ecológica da percepção direta, em especial os conceitos de affordance, affordance social e mutualidade. Em seguida, discutiremos algumas implicações da abordagem ecológica da noção de experiência na análise do conceito de habilidade social complexa.

Principia 21(2): 223-233 (2017). 


\section{A teoria ecológica da percepção direta}

Uma das teses centrais da teoria da percepção direta (TPD), também denominada teoria da percepção/ação, postula que organismos em geral, inclusive seres humanos, são capazes de perceber diretamente informação intrinsecamente significativa do ambiente (com o qual compartilham uma história co-evolucionária) e agir imediatamente, sem a necessidade de deliberações prévias resultantes de representações e modelos mentais.

Na teoria da percepção direta, o conceito de affordance foi cunhado por James Gibson (1986) para designar a informação intrinsecamente significativa disponível no ambiente e propiciadora imediata de ações. Exemplos de affordances são as diversas possibilidades que um mesmo objeto, como uma pedra, propicia a diferentes espécies: a pedra é "pousável" para um pássaro, "contornável" para um inseto, "aquecível" como fonte de calor para um réptil, ou "jogável” para um ser humano.

Segundo Gibson (1986):

As affordances do ambiente são o que ele oferece ao animal, o que ele provê ou fornece, seja para bem ou para mal. Quero dizer com isso algo que se refere a ambos, ao ambiente e ao animal. Isso implica a complementaridade do animal e do ambiente (1986, p.127).

Gibson (1986) indica que as várias possibilidades de ação disponibilizadas no ambiente aos organismos que nele habitam estão diretamente relacionadas às características fisiológicas dos organismos e de seus nichos, características que, por sua vez, resultaram de processos de longa duração que propiciam a adaptação dos organismos ao ambiente. Desse modo, o corpo de cada espécie instancia uma trajetória de co-evolução adaptativa organismo/ambiente, indicadora viva de diferentes modos de agir. Exemplo de uma tal trajetória incorporada é a complexa história das barbatanas dos cetáceos, animais pertencentes a uma linhagem de organismos terrestres que se tornaram posteriormente marítimos. Os membros desses organismos, adaptados de início à locomoção em terra, se adaptaram posteriormente de modo gradual para permitir a locomoção em um meio líquido. Os cetáceos, então, teriam desenvolvido um novo padrão de locomoção que envolve movimentos ondulatórios verticais da coluna, diferentemente dos movimentos ondulatórios horizontais próprios da locomoção dos peixes, os quais possuem uma trajetória co-evolucionária de locomoção apenas em meio líquido (Uhenm 2010).

Nesse sentido, o corpo dos organismos indica o rumo evolucionário de sua espécie, pois têm incorporadas as diferentes soluções adaptativas exitosas que a espécie foi desenvolvendo e por meio das quais foi superando as variadas situações de risco resultantes da dinâmica ambiental, muitas vezes desafiadoras (como catástrofes naturais, o surgimento de novos predadores, a competição pelas fontes de alimento ou seu esgotamento, apontando apenas algumas).

Principia 21(2): 223-233 (2017). 
Uma hipótese da TPD é que soluções adaptativas que são incorporadas pelos organismos podem propiciar a emergência de padrões de ação (ou performances) mais complexos em situações igualmente novas. Como exemplo da capacidade de incorporação de performances complexas, necessárias à sobrevivência dos organismos, que envolvem a capacidade de percepção de affordances não redutíveis a instintos mecânicos, pode ser citado o caso de jovens mamíferos precocemente separados de suas famílias e retirados do contexto ecológico a que pertencem. Nesses casos, depois de adultos, os animais não podem ser simplesmente devolvidos ao meio natural porque não tiveram a possibilidade de incorporar, por processos de percepção/ação, performances necessárias a sua sobrevivência junto a indivíduos adultos de sua espécie.

Para Gibson (1986), organismos e meio ambiente são co-dependentes em um sentido evidente da perspectiva dos organismos, pois sem o ambiente apropriado os organismos se extinguiriam ou sequer teriam existido. Mas a co-dependência organismo/ambiente possui um sentido não tão evidente quando se trata do ambiente, pois, quando desprovido de vida, não se tem propriamente um meio ambiente, mas uma realidade física, como a da Terra antes do aparecimento da vida. Para compreender a relação de co-dependência organismo/ambiente, o conceito de nicho se mostra fundamental. Gibson (1986) oferece uma caracterização do conceito de nicho distinta da noção de habitat utilizada em geral para designar locais em que vivem os organismos. Para ele, um nicho “...é um conjunto de traços ambientais adequado para um animal ao qual ele se ajusta ... [o conceito de nicho] se refere mais a como um animal vive do que a onde ele vive ... um nicho é um conjunto de affordances" (p.128, destaque do autor e grifo nosso).

Uma questão relevante para a compreensão da TPD diz respeito à dinâmica inerente à relação organismo-ambiente: como é possível que a imensa diversidade de affordances e invariantes possibilite a existência (mais ou menos harmoniosa) entre os organismos? Afinal, em situações normais, não colapsamos uns com os outros, a despeito de haver tendências de conduta muitas vezes aparentemente conflitantes (tanto nas interações entre as diversas espécies quanto nas relações entre indivíduos da mesma espécie). Sem pretender oferecer uma solução satisfatória a essa questão, entendemos que Gibson (1986) ensaia uma resposta através do Principio de Mutualidade.

A relação forte de co-dependência organismo/nicho atende, segundo Gibson, ao princípio de mutualidade (1986, p.8). Segundo tal princípio, organismos e meio ambiente co-evoluem integradamente na medida em que as espécies se desenvolvem e se adaptam às mudanças ambientais, por sua vez alterando o ambiente e deixando nele traços de sua passagem, o que pode propiciar a emergência de novas possibilidades de ação para outros organismos. Um exemplo da envergadura do impacto ambiental da ação de organismos indicadora da relação de mutualidade é a própria composição atual da atmosfera terrestre, cuja taxa de oxigênio, apropriada para sus- 
tentar as formas de vida ora existentes, teria resultado da ação de bactérias capazes de realizar fotossíntese.

Assumindo que o ambiente constitui uma realidade física moldada pela atividade dos organismos ao longo do tempo, Gibson (1986) argumenta que o ambiente oferece uma "persistência sob mudança", isto é, possui uma invariância dinâmica que exerce um papel legiforme, como apontam Petrusz \& Turvey (2010). Por exemplo, uma paisagem pode ser alterada radicalmente por atividade vulcânica, mas o material expelido por vulcões possui uma composição propícia para o surgimento de rica variedade de vida vegetal que poderá, posteriormente, desenvolver-se e prosperar, o que permitirá, por sua vez, que animais também prosperem.

Gibson denomina invariantes estruturais e transformacionais os traços ecológicos estáveis retidos na memória dinâmica da relação organismo-ambiente ao longo dos processos co-evolucionários. A estabilidade aqui pressuposta não é absoluta, mas de natureza dinâmica, de "permanência sob mudança", utilizando a expressão cunhada por Gibson. Dentre esses traços ele destaca, por exemplo, as características estruturais das superfícies, como os meios (aéreo, terrestre ou aquático) nos quais os organismos se locomovem e, entre as invariantes transformacionais, os diferentes processos de locomoção (voo, nado, marcha, corrida, salto, entre outros) propiciados pelos distintos meios.

Partindo desses princípios centrais da TPD, em artigo que busca aproximar os estudos da Psicologia Social com a abordagem gibsoniana, McArthur \& Baron (1983) esboçam uma concepção de affordance social inspirados em uma caracterização de affordance proposta por Gibson (1986), segundo a qual:

As diferentes substâncias do ambiente têm diferentes affordances para nutrição e manufatura. Os diferentes objetos do ambiente têm diferente affordances para manipulação. Acima de tudo, outros animais propiciam (afford) um rico e complexo cenário de interações - sexuais, de predação, de cuidado mútuo, de luta, de jogo, cooperativas e comunicativas. $O$ que outras pessoas propiciam (afford) compreende todo o âmbito de significância social para os seres humanos. Prestamos especial atenção para a informação ótica e acústica que especifica o que a outra pessoa é, encoraja, ameaça e faz (p.135, tradução e destaques nossos).

Inspirados nessa caracterização de affordance, McArthur \& Baron (1983) descrevem as affordances sociais como sendo propriedades disposicionais coletivas que indicam possibilidades de ação que organismos oferecem a outros organismos com os quais compartilham uma história co-evolucionária. Os autores sugerem que, assim como a percepção de um moinho de vento em movimento revela invariantes estruturais e transformacionais presentes no moinho e no ambiente, também a dinâmica das ações dos agentes revela invariantes estruturais e sociais (p.221). Exemplos de invariantes sociais estruturais são a forma do corpo da espécie (como o número de seus 
membros, a disposição e a natureza de seus órgãos perceptuais, dentre outros) e as informações de hábitos coletivos presentes em seu nicho. Invariantes transformacionais sociais, por sua vez, se expressam nas ações que revelam a dinâmica motora do organismo em atividades específicas de alimentação, gesticulação, cuidados mútuos, proteção da progênie, resposta a ameaças, dentre outras.

Cabe ressaltar que, no caso das affordances sociais humanas, embora haja gestos específicos a culturas dadas, existem manifestações de emoção, especialmente nas expressões faciais como medo, alegria, surpresa ou raiva, cujo significado pode ser diretamente percebido e pode nortear a conduta do percebedor. Nesse sentido, ressaltam McArthur \& Baron (1983) que:

O destaque na relevância adaptativa das expressões de emoção desloca a ênfase nos estudos da percepção de emoções do âmbito da emoção como experiência fenomenal para o âmbito da emoção como guia da ação (McArthur \& Baron 1983, p.226, tradução nossa)

Enfatiza-se, assim, o foco externalista e contextual da experiência perceptual de modo a compreender o direcionamento da ação propiciado pela percepção direta de affordances sociais sem a necessidade de representações mentais.

A partir dos conceitos centrais da TPD apresentados, especialmente na noção de affordance social, discutiremos, na próxima seção, nossa hipótese de que práticas sociais humanas decorrentes da percepção de affordances sociais são relevantes para compreender padrões de ação colaborativa, bases da conduta moral significativa.

\section{Affordances sociais e habilidades complexas na experiência humana}

Nesta segunda seção discutiremos como o conceito de affordance social pode auxiliar a compreender aspectos relevantes da constituição de habilidades sociais complexas, aspectos esses que, entendemos, não são devidamente levados em conta por abordagens representacionistas da mente e da ação. Nesse sentido, discutiremos as seguintes teses: (1) ações sociais de natureza colaborativa/altruísta desempenharam um papel fundamental na história co-evolucionária, adaptativa e de longa duração da espécie humana e (2) que tais ações envolvem a percepção direta de affordances sociais e ainda continuam a desempenhar relevante papel na sociedade humana.

No que se refere à primeira tese, cabe inicialmente destacar exemplos de estudos antropológicos, como os realizados por Gracia et al. (2009) e Hublin (2009), que fornecem evidências paleontológicas de ações sociais altruístas de ancestrais humanos. Gracia et al. (2009) recuperaram o crânio de um indivíduo portador de necessidades especiais pertencente a grupo de caçadores/coletores de ancestrais humanos cuja

Principia 21(2): 223-233 (2017). 
sobrevivência, por pelo menos cinco anos, não teria sido possível sem o auxílio e apoio dos demais membros do grupo social a que pertencia. Esta e outras evidências paleontológicas desafiam abordagens pessimistas da conduta humana nas áreas de antropologia, biologia e economia (Alexander 1987, Nowak \& Sigmund 1998, Trivers 1971, Kagel \& Roth 1995).

Segundo a concepção pessimista, o altruísmo humano seria ilusório, apenas conveniente para mascarar interesses individuais e egoístas, muitos deles redutíveis à preservação e transmissão da linhagem genética do indivíduo. Bowles \& Gintis (2011) reconhecem que modelos pessimistas que, por exemplo, consideram que as ações altruístas se restringem efetivamente ao círculo familiar dos agentes ou são praticadas apenas para recebimento de recompensas futuras, o denominado "altruísmo recíproco", conseguem explicar vários padrões de ação colaborativa. No entanto, eles ressaltam que tais modelos centralizados no interesse individual dos agentes são incapazes de explicar porque os seres humanos mantêm formas colaborativas de ação em círculos sociais mais amplos que os familiares e em situações incapazes de gerar qualquer expectativa futura de ganho ou obtenção de vantagem. Bowles \& Gintis (2011, p.3) defendem que práticas colaborativas que envolvem emoções como a empatia associada ao altruísmo acompanham a trajetória co-evolucionária dos seres humanos e se tornaram fundamentais para a própria preservação da espécie.

No que diz respeito à segunda tese, segundo a qual affordances sociais de natureza colaborativa ainda desempenham relevante papel nas sociedades humanas, a capacidade transcultural de reconhecimento de emoções sugere, segundo McArthur \& Baron (1983, p.226), que a expressão de certo tipo de emoções pode ter evoluído para fornecer informação de relevância adaptativa para a espécie humana como um todo até a atualidade. A informação fornecida pelas affordances sociais, dentre elas as expressões corporais de emoções, inclui informação significativa de perigo iminente, empatia, repreensão, encorajamento, ameaça, solidariedade, cooperação, cuidado mútuo, dentre muitas outras. Segundo McArthur \& Baron:

[...] emoções podem ser consideradas como affordances sociais no sentido de que elas propiciam condutas interpessoais variadas. Por exemplo, possivelmente raiva provoque afastamento, enquanto que alegria encoraja aproximação (1983, p.226, tradução nossa)

Entendemos que a abordagem da TPD permite compreender importantes aspectos da dinâmica da gestualidade humana ao considerar as invariâncias transformacionais das affordances sociais. Em outros termos, a TPD permite compreender como a gestualidade dos agentes em interação propicia um fluxo compartilhado de ações, promovendo ajustes e correções nas ações coletivas em consonância com a dinâmica da gestualidade dos agentes.

Exemplos de como opera a dinâmica da gestualidade humana decorrente da per-

Principia 21(2): 223-233 (2017). 
cepção de affordances sociais são encontrados em circunstâncias cotidianas: na cultura ocidental, na maioria das vezes em que alguém é apresentado a outrem, as pessoas estendem suas mãos em saudação, ou, em outras culturas, fazem um gesto com a cabeça ou uma reverência, a partir dos quais as pessoas começam a interagir. Na cultura ocidental, estender a mão não exige deliberações prévias, trata-se de hábito social incorporado realizado em concomitância à percepção das affordances sociais de saudação que o propiciam. No entanto, o gesto de estender a mão e, por exemplo, apertar a mão em excesso ou aplicar uma força que desequilibre a outra pessoa quebra a dinâmica do hábito social incorporado indicador de saudação. Tal quebra promove o ajuste na dinâmica da interação entre os agentes: a affordance social de apertar as mãos, saudação inicialmente indicadora de cordialidade, passa a propiciar ações decorrentes da percepção de informação que significa desconfiança e ameaça. Cabe acrescentar que, se a possibilidade de ação diretamente oferecida pela gestualidade do aperto de mão deixar de significar diretamente cordialidade, outras dinâmicas gestuais poderão ser adotadas, permitindo aos agentes uma atualização de seus hábitos sociais incorporados, tanto para possibilitar o fluxo de ações cordiais quanto o de ações ameaçadoras.

O exemplo acima permite ressaltar, ademais, que certas affordances sociais de alta relevância na trajetória co-evolucionária humana podem indicar diretamente possibilidades de ação em situações transculturais e até entre diferentes espécies. Por exemplo, a ação de correr na presença de um animal predador indica ao predador que o animal que corre está amedrontado e pode ser uma presa em potencial, seja ele uma gazela ou um ser humano.

Na medida em que os seres humanos constituem uma espécie social, parece razoável considerar que affordances indicadoras de cordialidade, ajuda mútua, lealdade, confiança, amizade, entre outras, sejam mais frequentes e numerosas do que affordances de ameaça, disputa, traição, desconfiança e inimizade, sob pena de inviabilizar o próprio estabelecimento de relações interpessoais para além do círculo familiar. Para justificar esta tese, destacamos que a própria dinâmica das ações cotidianas é indicadora tácita da confiança mútua que os agentes depositam nos outros a seu redor, mesmo desconhecidos, por exemplo, quando saem de suas casas para realizar qualquer atividade. É claro que a manutenção de hábitos sociais de confiança mútua interpessoal é também contexto-dependente e será alterada em circunstâncias afetadas por situações-limite, como guerras ou convulsões sociais.

Um exemplo que consideramos possa esclarecer a prevalência de affordances colaborativas em situações corriqueiras diz respeito ao papel da empatia cinética propiciada por affordances sociais de cooperação. Por empatia cinética entendemos a capacidade de um agente propiciar diretamente respostas colaborativas em outros agentes engajados na realização de uma atividade coletiva (Reynolds \& Reason 2012, p.12). Exemplos de tal empatia podem ser encontrados em situações do cotidiano: quando

Principia 21(2): 223-233 (2017). 
vemos alguém empurrando um automóvel avariado e começamos a empurrar também; quando seguramos um desconhecido que se desequilibra na rua e evitamos que caia; quando estamos realizando uma tarefa que obviamente excede a força de um único agente e outros auxiliam ritmicamente em sua realização, como no remo, o deslocamento de grandes objetos e outras atividades cuja execução exija ações coordenadas.

Além disso, cabe ressaltar que affordances sociais indicadores de repreensão, recriminação ou admoestação (especialmente expressões faciais) atuam como limitadores de ações não colaborativas (egoístas, desleais ou agressivas, por exemplo), permitindo aos agentes, especialmente aos mais jovens ou socialmente inexperientes, ajustar ou alterar suas ações. Desse modo, frequentemente affordances sociais de repreensão oferecem feedbacks que possibilitam o abandono de hábitos de ação percebidos como egoístas ou individualistas e a geração, atualização e incorporação de novos hábitos. Consequentemente, os feedbacks oferecidos por affordances sociais de repreensão encorajam a geração e ajuste de habilidades colaborativas geradoras de interações sociais complexas - de confiança mútua, amizade, lealdade e, especialmente, de empatia e altruísmo.

Para finalizar esta seção, cabe ressaltar que as possibilidades de ação disponibilizadas pelas affordances sociais colaborativas não são determinantes no sentido forte de estarem cristalizadas ou serem meras promotoras de condicionamento dos agentes: a própria sociedade promove ajustes, como vimos, nos hábitos sociais humanos de longa duração em função da dinâmica adaptativa dos processos co-evolucionários.

Em outros termos, a indicação de possibilidades de ação resultantes das affordances em geral, inclusive as sociais, pode atualizar-se em função de mudanças ambientais, culturais e tecnológicas. Além disso, cabe destacar também que os hábitos sociais humanos decorrentes de affordances sociais são aqueles hábitos incorporados pela espécie humana ao longo de sua história co-evolutiva (tais como bipedalismo, cuidados com a progênie, a expressão de emoções básicas, entre outros). Em se tratando de hábitos incorporados, as affordances sociais vão também sendo coletivamente moldadas e atualizadas de modo a permitirem performances sociais habilidosas em contextos que se complexificam, por exemplo, por meio do uso de novas tecnologias.

\section{Comentários finais}

Sugerimos que a teoria da percepção direta pode nos auxiliar a compreender aspectos relevantes da dinâmica social humana, especialmente a de natureza colaborativa, resultantes da percepção direta de affordances sociais. Cabe ressaltar que, em última análise, uma dinâmica social majoritariamente colaborativa parece necessária para a própria existência, preservação e atualização de grupos sociais.

Principia 21(2): 223-233 (2017). 
O exercício de habilidades sociais complexas humanas foi atribuído pela teoria representacionista da mente e da ação a mecanismos internos que envolveriam, segundo tal teoria, representações mentais e modelos de planejamento da conduta futura. Assim sendo, ações consideradas social ou moralmente significativas resultariam de processos inferenciais e generalizações decorrentes de representações mentais dos agentes morais.

Em contraposição, procuramos mostrar que haveria formas complexas de experiência perceptual que permitiriam a percepção direta de informação intrinsecamente significativa e socialmente necessária por estabelecerem relações de co-dependência entre os membros de grupos sociais. Entendemos que a percepção direta de affordances sociais possibilita a prática de ações que envolvem habilidades complexas necessárias para a preservação e atualização do grupo social (tais como altruísmo, repreensão, amizade, colaboração, lealdade, censura, entre outras) sem a necessidade da mediação de representações mentais. Em suma, ao mesmo tempo em que affordances sociais possibilitam performances complexas, elas também podem restringir ou limitar possibilidades de ação que potencialmente inviabilizam a preservação do grupo.

Assim sendo, podemos concluir que pelo menos parte das habilidades sociais complexas necessárias à ação considerada moralmente significativa resultaria também de interações colaborativas, processos de feedback e restrições propiciadas pela percepção direta de affordances sociais. Desse modo, entendemos que uma teoria mais robusta da agência moral poderia beneficiar-se ao considerar aspectos da experiência perceptual relacionados à percepção direta de affordances sociais, especialmente os que possibilitam ações colaborativas.

\section{Agradecimentos}

Este trabalho foi elaborado a partir de pesquisas realizadas conjuntamente com Maria Eunice Q. Gonzalez (UNESP), José Artur Quilici-Gonzalez (UFABC) e com membros do GAEC Grupo Acadêmico de Estudos Cognitivos da UNESP e do Grupo CLE-Auto-organização da UNICAMP.

\section{Referências}

Alexander, R. D. 2017. The Biology of Moral Systems. Disponível em https://pdfs . semanticscholar. org/ddfc/e0cb57c3dccee5d9029c310aaa1cb63ae4d2 . pdf. Acesso em 24/05/2017.

Bowles, S.; Gintis, H. 2011. A Cooperative Species: Human reciprocity and its evolution. Princeton: Princeton University Press.

Fodor, J. A.; Pylyshyn, Z. W. 2014. Minds without Meanings: An Essay on the Content of Concepts. Cambridge: MIT Press.

Principia 21(2): 223-233 (2017). 
Gibson, J. J. 1986. The Ecological Approach to Visual Perception. Boston: Houghton-Miffin.

Gracia A. et al. 2009. Craniosynostosis in the Middle Pleistocene human Cranium 14 from the Sima de los Huesos, Atapuerca, Spain. Proceedings of the National Academy of Sciences of the United States of America 106: 6573-6578. Disponível em http: //www .pnas .org/ content/106/16/6573.full.pdf. Acesso em 11/05/2017.

Haselager, W. F. G. 2004. O mal estar do representacionismo: sete dores de cabeça da Ciência Cognitiva. In: A. Ferreira; M. E. Q. Gonzalez; J. G. Coelho (eds.) Encontros com as Ciências Cognitivas, Volume 4. São Paulo: Coleção Estudos Cognitivos.

Hublin, J. J. 2017. The prehistory of compassion. Proceedings of the National Academy of Sciences of the United States of America 106(16). Disponível em http: / / www . pnas . org/ content/106/16/6429. full.pdf. Acesso em 23/05/2017.

Kagel, J.; Roth, A. (eds.) 1995. The Handbook of Experimental Economics. Princeton: Princeton University Press.

McArthur, L. Z.; Baron, R. M. 1983. Toward an Ecological Theory of Social Perception. Psychological Review 90(3): 215-238.

Nowak, M.; Sigmund, K. 1998. The Dynamics of Indirect Reciprocity. Journal of Theoretical Biology 194: 561-574.

Reynolds, D.; Reason, M. 2012. Kinesthetic Empathy in Creative and Cultural Practices. Chicago: University of Chicago Press.

Petrusz, S. C.; Turvey, M. T. 2010. On the distinctive features of ecological laws. Ecological Psychology 22: 44-68.

Trivers, R. 1971. The Evolution of Reciprocal Altruism. Quarterly Review of Biology 46(1): 35-57. Disponível em https://greatergood.berkeley.edu/images/uploads/ Trivers-EvolutionReciprocalAltruism.pdf. Acesso em 25/05/2017.

Turvey, M. T. 1992. Affordances and prospective control: An outline of the ontology. Ecological Psychology 4: 173-187.

Uhen, M. D. 2010. The Origin(s) of Whales. Annual Review of Earth and Planetary Sciences 38: 189-219.

MARIANA C. BROENS

UNESP - CNPq

mbroens@marilia. unesp. br 